\title{
Opinion
}

\section{Mache Papanicolaou (1890-1982), the dedicated companion of the great benefactor: An interview with Dr Julie Kokkori, one of the only living relatives of Dr George N. Papanicolaou}

\author{
IOANNIS N. MAMMAS ${ }^{1-3}$, CHRYSSIE KOUTSAFTIKI ${ }^{4}$, \\ ALEXIA PAPATHEODOROPOULOU ${ }^{5}$ and DEMETRIOS A. SPANDIDOS ${ }^{1}$
}

\author{
${ }^{1}$ Laboratory of Clinical Virology, School of Medicine, University of Crete, 71003 Heraklion; \\ ${ }^{2}$ First Department of Paediatrics, University of Athens School of Medicine, 11527 Athens; \\ ${ }^{3}$ Paediatric Clinic, Aliveri, 34500 Island of Euboea; ${ }^{4}$ Paediatric Intensive Care Unit (PICU), 'Penteli' Children's Hospital, \\ 15236 Athens; ${ }^{5}$ Paediatric Intensive Care Unit (PICU), ‘Aglaia Kyriakou’ Children's Hospital, 11527 Athens, Greece
}

Received July 22, 2019; Accepted August 26, 2019

DOI: $10.3892 /$ etm.2019.7951

\begin{abstract}
Mache Papanicolaou (Volos, Greece, 1890 - Miami, Florida, USA, 1982) was the soul of absolute dedication to research, science and humanity of her lifelong partner, Dr George N. Papanicolaou (Kymi, Greece, 1883 - Miami Florida, USA, 1962). Her devotion to him, her endless support during their first years in the USA, as well as during the period before the approval of the Pap smear test and her selfless contribution to this revolutionary work were invaluable, indeed. In this article, which is dedicated to the memory of Mache Papanicolaou, we have the great honour to host the testimony of one of the only living relatives of Dr George N. Papanicolaou. Dr Julie Kokkori is the granddaughter of Nasos N. Papanicolaou (Kymi, Greece, 1880-Athens, Greece, 1958), the oldest brother of Dr George N. Papanicolaou, and daughter of the niece of Dr George N. Papanicolaou, Maria Kokkori (Trikala, Greece, 1918 - Athens, Greece, 2012), author of the first book in the Hellenic literature on the life of Dr George N. Papanicolaou entitled 'George N. Papanicolaou: through his life and work'.
\end{abstract}

\section{Contents}

1. Introduction

2. Questions and Answers

Correspondence to: Professor Demetrios A. Spandidos, Laboratory of Clinical Virology, School of Medicine, University of Crete, 71003 Heraklion, Greece

E-mail: spandidos@spandidos.gr

Key words: Mache Papanicolaou, George N. Papanicolaou, Pap smear test, Cornell, Miami, Euboea, Greece

\section{Introduction}

Born on the island of Euboea, Dr George N. Papanicolaou (Kymi, Greece, 1883 - Miami Florida, USA, 1962), the inventor of the Pap smear test and founder of Exfoliative Cytopathology, is undoubtedly one of the greatest modern scientists worldwide and the most significant Greek medical doctor of the modern era (1-5). In 1904, at the age of 21, Dr George N. Papanicolaou received his medical degree with honours from the University of Athens School of Medicine and fulfilled his military duties (1). It was then that he assessed his return to his island to practice the medical profession, as well as the prospect of becoming a military doctor. However, both scenarios would be a personal defeat for him. In the book of Maria Kokkori (Trikala, Greece, 1918 - Athens, Greece, 2012), Dr George N. Papanicolaou's words reflect his refusal to practice the medical profession at that time in Greece (1): 'It is impossible to practice a profession; I prefer to kill myself... I can only indulge in philosophy... No, I do not want to become a military doctor. I want to stay free, to feel the joy of the struggle of life. I am not scared by the sea. I want my freedom, my sweet freedom'. Since then, his whole life remained devoted to science. He writes to his parents (1): 'My ideal is not to become rich, or to be happy, but to work, to act, to create, to do something worthy of an ethical and strong man'. Among other thoughts, he writes about his self-discipline (1): 'A man who strives to create a future has no right to feel and to be nostalgic. Anyone who wants to succeed must know how to drown the pulses of his heart'. He also writes elsewhere (1): 'The danger came from myself. Doubts, weakness, some instincts, some aristocratic tendencies; that was the great danger. Now that all these are missing, there is absolutely no fear'. His whole life has been characterised by his saying 'I live to serve life', which has been inscribed on his bronze statue situated close to the new Evripos bridge called 'George N. Papanicolaou Bridge'; this bridge is connecting the island of Euboea to the mainland Greece. 
Undoubtedly, the real reason why Dr George N.Papanicolaou was absolutely dedicated to research, science and humanity was his wife Mache Papanicolaou (Volos, Greece, 1890 - Miami, Florida, USA, 1982). Her devotion to her husband, her endless support during their first years in the USA, as well as during the period before the approval of his test and her selfless contribution to Dr George N. Papanicolaou's efforts were invaluable, indeed (1-5). Recently, the student of Dr George N. Papanicolaou, Dr Neda Voutsa-Perdiki, author of the book entitled 'Dr George and Mache-Mary Papanicolaou - As I knew them', said about Mache (6): 'His wife, Mache-Mary Papanicolaou, offered him the main support during the first years in the USA as well as during his research hard years. She was always standing by him, as a 'rock', as a real 'rock'. Despite her short stature, she was always there to listen to him, to tell him her opinion, to support him. She was his lifelong dedicated companion. She was his whole life. She was always proud of him. And he was always proud of her'.

In this article, which is dedicated to the memory of Mache Papanicolaou (Figs. 1 and 2), we have the great honour to host the testimony of one of the only living relatives of Dr George N. Papanicolaou's family, Dr Julie Kokkori. Dr Kokkori (Fig. 3) is one of the grandchildren of Nasos N. Papanicolaou (Kymi, Greece, 1880 - Athens, Greece, 1958), the oldest brother of Dr George N. Papanicolaou. Her mother, Maria Kokkori, niece of Dr George N. Papanicolaou, was the author of the first book in the Hellenic literature on the life of Dr George N. Papanicolaou entitled 'George N. Papanicolaou: through his life and work'. This book was published for the first time in 1985 by Kedros Editions (Fig. 4), while in 2008, it was translated into English (for more information, visit the official website on the life of Dr George N. Papanicolaou created by Dr Kokkori; www.dr-pap.com). In the context of the '5th workshop on Paediatric Virology', which will be held in October 12th, 2019, in Sparta, Greece, Dr Kokkori will announce and hand over the '2019 George N. Papanicolaou Humanitarian Award' to Professor George P. Chrousos, Professor Emeritus of Paediatrics and Endocrinology at the University of Athens School of Medicine, in Athens, Greece.

\section{Questions and Answers}

Question: Mache-Mary Papanicolaou has been well described in the book of your mother, Maria Kokkori, entitled 'George N. Papanicolaou: through his life and work'. What was her real name, Mache or Mary? How did your mum used to call her? Answer: Her name was Andromache Mavroyeni. After her marriage to Dr George N. Papanicolaou, she got the surname of her husband. She remained known in the USA as Mary due to the difficulty her name 'Andromache' or 'Mache' had to be pronounced correctly by the Americans. For this reason, the Papanicolaou couple adopted the name 'Mary', honouring thus and the day of her birth, 15th of August 1890. My mum was

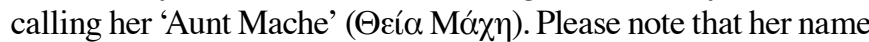
'Andromache' is ancient Greek and means the battle against men.

Question: Who was Mache, where was she born and how did she meet Dr George N. Papanicolaou?

Answer: Mache was the daughter of the officer of the Hellenic Army, Aristarchos Mavroyenis, and she was a descendant

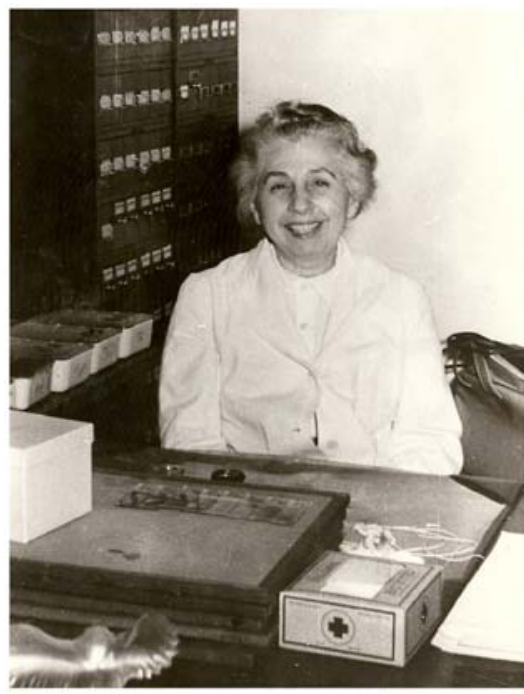

Figure 1. Mache Papanicolaou at Dr George N. Papanicolaou's laboratory in New York, USA.

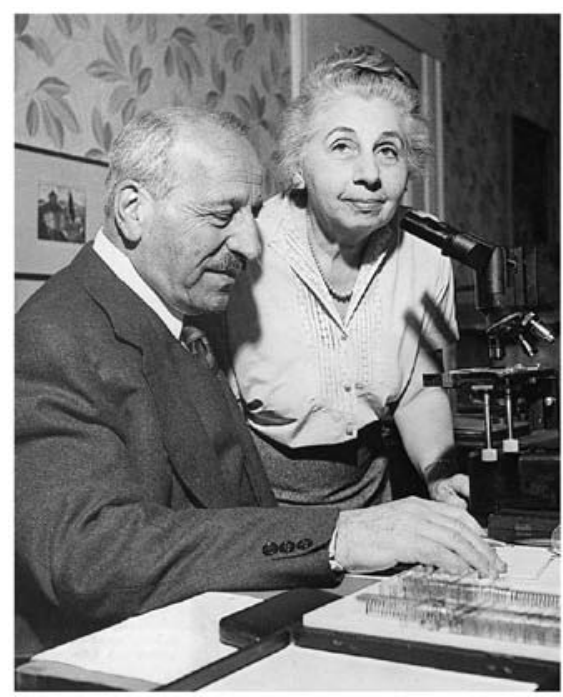

Figure 2. Mache Papanicolaou with Dr George N. Papanicolaou at their house in Douglaston, New York, USA.

of the heroine of the Hellenic Revolution in 1821, Manto Mavroyenous. She was born in Volos, Thessaly, where her family had visited because of her father's duties. She met George for the first time on one of her summer excursions with her family in Kymi on the island of Euboea and they got married in Athens on September 15, 1910. As my mother, Maria Kokkori, writes in her book, Dr George N. Papanicolaou found in Mache a character full of courage, enormity, bravery and dignity. Their lives proved that his insight was absolutely accurate.

Question: During their first years in the USA, as well as during the period before the approval of Pap test, she was standing by Dr George N. Papanicolaou as a 'rock', as a real rock. How important was her support to Dr George N. Papanicolaou? Answer: In 1913, George and Mache departed together for the USA, where they arrived just with \$250. Mache, always with dignity, worked in a tailor's shop, a grocery store, to 


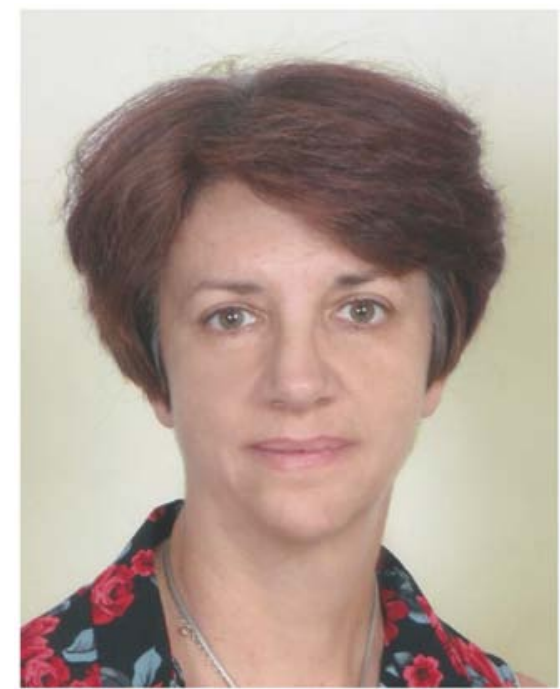

Figure 3. Dr Julie Kokkori, one of the only living relatives of Dr George N. Papanicolaou.

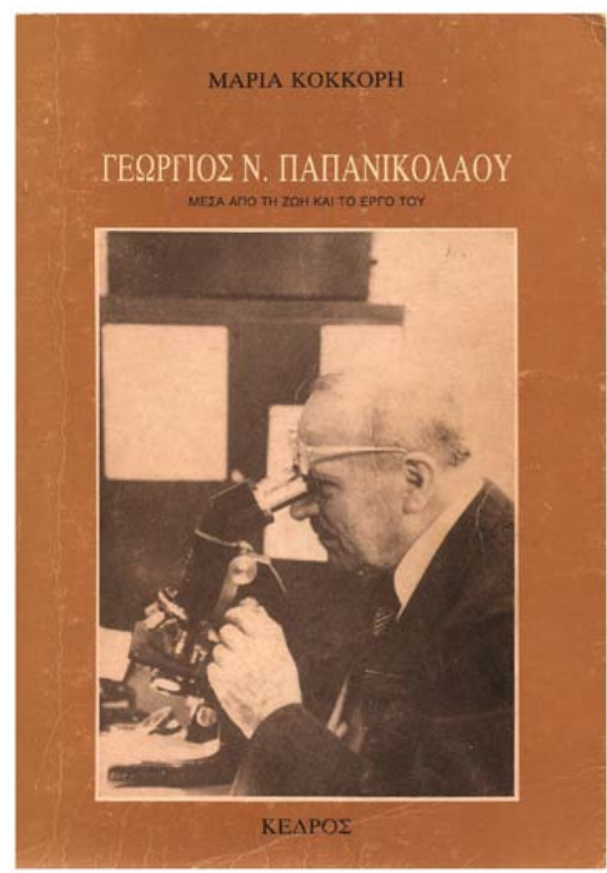

Figure 4. The first book in the Hellenic literature on the life of Dr George N Papanicolaou entitled 'George N. Papanicolaou: through his life and work' by Maria Kokkori, neice of Dr George N. Papanicolaou.

secure a livelihood. Later on, she became his driver, his laboratory technician, his secretary and his valuable partner. Mache remained for 52 years his devoted companion. At the beginning, this path was full of difficulties, but ended up to a scientific work recognized worldwide. In this long and laborious path, Mache served as a devotional and indefatigable partner in the research that Dr Pap had set as the purpose of his life. We are used to say that behind every great invention is a great woman. Mache was for George the hidden soul of his success. Women who survive cervical cancer due to the Pap smear test globally feel grateful to both, Mrs. and Dr Papanicolaou, indeed.
Question: She was an exceptional companion following Dr George N. Papanicolaou's exhaustive rhythm of work at Cornell University continuously for half a century. How difficult was this, indeed?

Answer: It was extremely difficult, long-lasting and intensive. George was a dedicated, hard-working scientist. He did not take any holidays, he used to work seven days a week. Mache would manage household and laboratory affairs, and this was very difficult.

Question: In 1957, the couple decided to make their first trip to Greece, after almost 44 years of continuing research work in the USA. What were her memories from this trip?

Answer: Excellent; she had enjoyed that trip. Certainly, most of all, she had enjoyed the reception by our relatives and friends in Kymi. The laid table at his house, the delicious well-known figs, the famous 'baklava', but especially the warm family atmosphere, were some of the memories that she was used to recall until the end of her life. During that trip, she promised to visit Greece, again, with George. However, on February 19, 1962, George died of myocardial infarction, almost three months after their arrival in Miami. She did not visit Greece again.

Question: She had never made any comment about the failure of Dr George N. Papanicolaou to be nominated for the Nobel Prize. Was this another proof of the quality of her personality? Answer: Mache was a very kind woman. The value of her personality was of high quality. No, she had never made any comment about the Nobel Prize case. However, this was not a matter of failure. As Dr Neda Voutsa-Perdiki has explained in her recent interview, this was a matter of unluckiness, not failure.

Question: When Dr George N. Papanicolaou accepted the proposal to run a cancer research Institute in Miami Beach, Florida, the couple moved to Florida at the end of 1961. This was another critical life decision...

Answer: Yes, she followed George's decision for one more time. After nearly 50 years at Cornell, the decision to leave New York was for Mache a very difficult one, indeed.

Question: How did she spend the rest of her life, after Dr George N. Papanicolaou's death?

Answer: After her husband's sudden death on February 19, 1962, Mache decided not to leave Miami, even though her life there would be extremely lonely. Thus, committed to Dr George N. Papanicolaou's work, she felt that she had to stay there to attend the development of the Institute. Every morning, she continued to visit the Dr Pap Lab in Miami and supervise its function. She was proud that Dr George N. Papanicolaou's dream was fulfilled, even though this happened after his death.

Question: What has been the most significant honour or award that she has received up to date?

Answer: Mache was present in almost all the events that were held to honour Dr George N. Papanicolaou, after his death. On May 18, 1978, the White House organized an official ceremony on the occasion of the issuing of the American stamp for Dr George N. Papanicolaou. During this event, she was honoured 
by the White House and personally by the wife of the US President, Rosalynn Carter, and Mrs. Pap made a short, but extremely touching speech. She passed away on October 13, 1982, at the age of 92. Since then, several events honouring the memory of Mache Papanicolaou have been performed. In the near future, there will also be a film about the life of Mache.

Question: In the recent book by Dr Neda Voutsa-Perdiki, the author describes Mache welcoming her. What was her contribution to medical students and young medical scientists of her era?

Answer: She was always very supportive to young scientists, who were visiting Dr George N. Papanicolaou's Lab at Cornell University, and she was always very glad to welcome any new physician, who would ask to be trained by them. I think that she was inspired by Dr George N. Papanicolaou's spirit to disseminate and teach his Pap test, to as many scientists as possible and to help them during their training.

Question: If Mache lived today, would she support the scientific efforts of the Paediatric Virology Study Group (PVSG) as well as the newly founded Institute of Paediatric Virology (IPV) based on the island of Euboea in Greece?

Answer: First of all, I consider your project run by a group of young paediatricians and junior researchers, as well as supported by so distinguished worldwide experts as very significant. Your scientific attempt to offer your ideas on the scientific field of Paediatric Virology to the international medical community and to create a global initiative in Greece, on the homeland of George and Mache Papanicolaou, is fantastic, indeed, and you deserve congratulations for this. Regarding your question, Mache would certainly have been very supportive to you as to every young doctor trying the best for science and humanity. Today, more than ever before, a scientist, who lives in the province, can be a citizen of the word. The evolution of technology and the ever-expanding applications of the internet make it easier than ever for a global targeting initiative, which depends on the capabilities of its members, to be based on the homeland island of George and Mache Papanicolaou. I wish you all the best in your scientific efforts.
Question: Thank you for this great honour to prepare together this article dedicated to the memory of Mache Papanicolaou as well as for your wishes! We look forward to your honorary presence in Sparta in October.

\section{Acknowledgements}

This article is published in the third supplement issue of the Experimental and Therapeutic Medicine, which is dedicated to Paediatric Virology. This edition is performed in the context of the '5th workshop on Paediatric Virology' (Sparta, Greece, October 12, 2019) organized by the Paediatric Virology Study Group (PVSG) and supported by the Department of Clinical Virology of the University of Crete School of Medicine and the First Department of Paediatrics of the University of Athens School of Medicine. We would like to thank Dr Julie Kokkori for this educational and inspirational interview-style article. We would also like to thank all the members of the PVSG for their interesting questions to Dr Kokkori and their valuable comments.

\section{References}

1. Kokkori M: George N. Papanicolaou: through his life and work. Kedros Editions, Athens, 2005 (In Greek).

2. Voutsa-Perdiki N: DrGeorge and Mache-Mary Papanicolaou - As I knew them. Medical Council of Athens, Athens, 2016 (In Greek).

3. Mammas IN and Spandidos DA: George N. Papanicolaou (1883-1962): Fifty years after the death of a great doctor, scientist and humanitarian. J Buon 17: 180-184, 2012.

4. Mammas IN and Spandidos DA: George N. Papanicolaou (1883-1962): Studying his first published article in Science 100 years on. J Buon 20: 1643, 2015.

5. Mammas IN and Spandidos DA: Four historic legends in human papillomaviruses research. J Buon 20: 658-661, 2015.

6. Mammas IN and Spandidos DA: George N. Papanicolaou (1883-1962), an exceptional human, scientist and academic teacher: An interview with Dr Neda Voutsa-Perdiki. Exp Ther Med 14: 3346-3349, 2017.

(i) $\Theta$ This work is licensed under a Creative Commons Attribution-NonCommercial-NoDerivatives 4.0 International (CC BY-NC-ND 4.0) License. 